\title{
Epidemiology, clinical, immune, and molecular profiles of microsporidiosis and cryptosporidiosis among HIV/AIDS patients
}

This article was published in the following Dove Press journal:

International Journal of General Medicine

18 July 2012

Number of times this article has been viewed

\author{
Roger Wumba' \\ Benjamin Longo-Mbenza ${ }^{2}$ \\ Jean Menotti ${ }^{3,4}$ \\ Madone Mandina ${ }^{5}$ \\ Fabien Kintoki ${ }^{5}$ \\ Nani Hippolyte Situakibanza ${ }^{1,5}$ \\ Marie Kapepela Kakicha ${ }^{6}$ \\ Josue Zanga' \\ Kennedy Mbanzulu-Makola' \\ Tommy Nseka' \\ Jean Pierre Mukendi' \\ Eric Kendjo ${ }^{7}$ \\ Jean Sala' \\ Marc Thellier ${ }^{7,8}$ \\ 'Department of Tropical Medicine, \\ Infectious and Parasitic Diseases, \\ Department of Parasitology, University \\ Clinic of Kinshasa, Faculty of Medicine, \\ University of Kinshasa, Kinshasa, Congo; \\ ${ }^{2}$ Faculty of Health Sciences, Walter \\ Sisulu University, Eastern Cape, South \\ Africa; ${ }^{3}$ Laboratory of Parasitology and \\ Mycology, Saint-Louis Hospital, Public \\ Assistance-Hospitals of Paris, Paris, \\ France; ${ }^{4}$ Faculty of Medicine, Lariboisière- \\ Saint-Louis, University of Paris VII, Paris, \\ France; ${ }^{5}$ Department of Internal Medicine, \\ University Clinic of Kinshasa, Faculty \\ of Medicine, University of Kinshasa, \\ Kinshasa, Congo; 'Department of Pediatrics, \\ University Clinic of Kinshasa, Faculty of \\ Medicine, University of Kinshasa, Kinshasa, \\ Congo; ${ }^{7}$ National Center for Malaria \\ Research, AP-HP, CHU Pitie Salpêtrière, \\ Paris, France; ${ }^{8}$ Laboratory of Parasitology \\ and Mycology, Pitié Salpêtrière Hospital, \\ Public Assistance-Hospitals of Paris, Pierre \\ and Marie Curie University, Paris, France
}

Correspondence: Benjamin Longo-Mbenza Walter Sisulu University, Faculty of Health Sciences, Private Bag XI, Mthatha, 5II7, Eastern Cape, South Africa

Tel +27 732822843

Email longombenza@gmail.com
Background: The objective of this study was to determine the prevalence of intestinal parasites, with special emphasis on microsporidia and Cryptosporidium, as well as their association with human immunodeficiency virus (HIV) symptoms, risk factors, and other digestive parasites. We also wish to determine the molecular biology definitions of the species and genotypes of microsporidia and Cryptosporidium in HIV patients.

Methods: In this cross-sectional study, carried out in Kinshasa, Democratic Republic of the Congo, stool samples were collected from 242 HIV patients ( 87 men and 155 women) with referred symptoms and risk factors for opportunistic intestinal parasites. The analysis of feces specimen were performed using Ziehl-Neelsen stainings, real-time polymerase chain reaction (PCR), immunofluorescence indirect monoclonal antibody, nested PCR-restriction fragment length polymorphism, and PCR amplification and sequencing. Odds ratio (OR) and 95\% confidence intervals were used to quantify the risk.

Results: Of the 242 HIV patients, $7.8 \%, 0.4 \%, 5.4 \%, 0.4 \%, 2 \%, 10.6 \%$, and $2.8 \%$ had Enterocytozoon bieneusi, Encephalitozoon intestinalis, Cryptosporidium spp., Isospora belli, pathogenic intestinal protozoa, nonpathogenic intestinal protozoa, and helminths, respectively. We found five genotypes of E. bieneusi: two older, NIA1 and D, and three new, KIN1, KIN2, and KIN3. Only $0.4 \%$ and $1.6 \%$ had Cryptosporidium parvum and Cryptosporidium hominis, respectively. Of the patients, $36.4 \%, 34.3 \%, 31 \%$, and $39 \%$ had asthenia, diarrhea, a CD4 count of $<100$ cells $/ \mathrm{mm}^{3}$, and no antiretroviral therapy (ART), respectively. The majority of those with opportunistic intestinal parasites and C. hominis, and all with C. parvum and new E. bieneusi genotypes, had diarrhea, low CD4+ counts of $<100$ cells $/ \mathrm{mm}^{3}$, and no ART. There was a significant association between Entamoeba coli, Kaposi sarcoma, herpes zoster, chronic diarrhea, and asthenia, and the presence of 28 cases with opportunistic intestinal parasites. Rural areas, public toilets, and exposure to farm pigs were the univariate risk factors present in the 28 cases with opportunistic intestinal parasites. In logistic regression analysis, a CD4 count of $<100$ cells $/ \mathrm{mm}^{3}(\mathrm{OR}=4.60 ; 95 \%$ CI $1.70-12.20 ; P=0.002)$, no ART $(\mathrm{OR}=5.00$; 95\% CI 1.90-13.20; $P<0.001)$, and exposure to surface water $(\mathrm{OR}=2.90 ; 95 \% \mathrm{CI} 1.01-8.40$; $P=0.048$ ) were identified as the significant and independent determinants for the presence of opportunistic intestinal parasites.

Conclusion: E. bieneusi and Cryptosporidium are becoming more prevalent in Kinshasa, Congo. Based on the findings, we recommend epidemiology surveillance and prevention by means of hygiene, the emphasis of sensitive PCR methods, and treating opportunistic intestinal parasites that may be acquired through fecal-oral transmission, surface water, normal immunity, rural area-based person-person and animal-human infection, and transmission of HIV. Therapy, including ART and treatment with fumagillin, is needed.

Keywords: diarrhea, Enterocytozoon bieneusi, Cryptosporidium hominis, Cryptosporidium parvum, risk factors, Africans submit your manuscript | www.dovepress.com

Dovepress

http://dx.doi.org/10.2147/IJGM.S32344
International Journal of General Medicine 2012:5 603-6II

(C) 2012 Wumba et al, publisher and licensee Dove Medical Press Ltd. This is an Open Access article which permits unrestricted noncommercial use, provided the original work is properly cited. 


\section{Introduction}

Enteric opportunistic parasites are associated with HIV/ AIDS, chronic diarrhea, education, occupation, residence in a slum, exposure to pets and animals, antiretroviral therapy (ART), use of public toilets, water, and practicing unsafe homosexual activity. ${ }^{1-20}$ The literature indicates that the prevalence of intestinal colonization due to microsporidia and Cryptosporidium are significantly higher among HIVinfected individuals with chronic diarrhea and CD4 lymphocyte counts of $<200$ cells $/ \mathrm{mm}^{3} .4,7,8,11,13,15,17,20$

In the Democratic Republic of the Congo (DRC), our country, the role of emerging pathogens such as Enterocytozoon bieneusi and Cryptosporidium spp. in HIV-infected patients, with and without diarrhea, has been identified using standard parasitological methods, such as light microscopy, Ziehl-Neelsen staining, the Fungi-Fluor ${ }^{\circledR}$ Kit for Fungal Detection, modified trichrome tests, and traditional polymerase chain reaction (PCR). ${ }^{21,22}$ However, the lack of sensitive and specific real-time PCR, nested PCR, and PCR-restriction fragment length polymorphism (RFLP) in the DRC has resulted in a lack of epidemiologic, clinical, and immune data related to intestinal parasites in HIV patients. Therefore, the objective of the present study was to determine the prevalence of intestinal opportunistic parasites, with special emphasis on microsporidia and Cryptosporidium, as well their association with HIV symptoms, risk factors, and other digestive parasites, and the molecular biology definition of the species and the genotypes of microsporidia and Cryptosporidium in HIV patients. Humanitarian collaboration with French hospitals (Saint-Louis, Pitié Salpêtrière, and INSERM UMR-S 945, Paris) has helped us to perform molecular biology in this work.

\section{Materials and methods Study design}

This descriptive and observational cross-sectional study took place between December 2009 and January 2012.

\section{Ethical considerations}

The institutional review boards and the Ethics Committee of the University of Kinshasa Faculty of Medicine approved the protocol of the study, which was conducted in compliance with the principles of the Helsinki Declaration II. The aim and the procedures of the study were explained to the participants and each participant (or a designated literate substitute, when necessary) signed an informed consent form.

\section{Study setting}

We randomly selected four main hospitals in Kinshasa, DRC: the Cliniques Universitaires de Kinshasa, which is a teaching hospital in the southwestern part of the city of Kinshasa, the General Referral Hospital of Kinshasa in central Kinshasa, the General Referral Hospital of Kintambo in the northeastern part of Kinshasa, and the Military Referral Hospital of Camp Kokolo in the western part of Kinshasa.

\section{Patients and clinical specimens}

We included 242 consecutive patients infected with HIV/AIDS. Epidemiologic, clinical, immune and laboratory data were collected from all participants.

\section{Epidemiology data}

Each participant was interviewed using a standardized, structured questionnaire to collect data regarding the prevalence of intestinal parasites (pooled, nonopportunistic, and opportunistic) and sociodemographic, environmental, and risk factors. The sociodemographic data were defined by gender, age, and socioeconomic status (low vs high by composite variables for education, occupation, and income). The environment was defined by the residence: rural, semirural, and urban areas. The risk factors for microsporidiosis and cryptosporidiosis included person-person infection by persons with chronic diarrhea via public toilets, ART, homosexual activities, through water storage, water pipes, swimming, and surface water; consumption of high-risk foods (fresh raw fruits and vegetables and food from street vendors); and zoonotic transmission routes (presence of specific domestic farm and pet animals in the home, such as dogs, pigs, goats, and chickens, and contact with droppings from these animals). We collected the risk-factor data prior to the interview and collection of the laboratory data.

\section{Clinical spectrum}

Medical students collected data regarding symptoms of the presence of HIV clinical manifestations, such as Kaposi sarcoma, herpes zoster, candidiasis, asthenia, and chronic diarrhea. We defined diarrhea as an average of $>3$ loose or liquid stools within a 24-hour period.

As defined by the World Health Organization, ${ }^{23}$ the four clinical stages of HIV/AIDS comprise stages 1-2 for preAIDS and stages 3-4 for AIDS.

\section{Parasitological diagnosis}

Samples and staining

Stool samples (one for each patient) were studied using optical microscopy (direct examination and specific stainings). 
Stools were collected in a vial containing phosphate-buffered saline and stored in a refrigerator at $4^{\circ} \mathrm{C}$ before handling. Microscopic analysis of feces and the direct concentration method according to the protocol of Ritchie ${ }^{24}$ were performed in the laboratory of the Department of Parasitology, University Clinics of Kinshasa. Ziehl-Neelsen staining (modified Henricksen-Pohlenz) was used for detecting Cryptosporidium sp. ${ }^{25}$

\section{Species identification}

\section{Indirect immunofluorescence}

We used indirect immunofluorescence with monoclonal antibodies, which is an effective method for the diagnosing of microsporidiosis, for identification of E. bieneusi and Encephalitozoon intestinalis. ${ }^{26}$

\section{Molecular methods}

\section{Extraction of DNA products}

DNA extraction was performed using a QIAmp DNA kit (QIAGEN, Courtaboeuf, France) in $50 \mu \mathrm{L}$ of phosphatebuffered saline and divided into an aliquot (1 Eppendorf ${ }^{\circledR}$ tube) and then stored at $-20^{\circ} \mathrm{C}$ prior to analysis, according to the manufacturer's instructions.

\section{Real-time PCR}

We carried out a real-time PCR for samples at the Saint Louis Hospital Parasitology mycology service in Paris, France, using a TaqMan ${ }^{\circledR} 7500$ Real Time PCR System (Applied Biosystems, Foster City, CA) for identification of the two species (E. bieneusi and E. encephalitozoon). ${ }^{27}$ The real-time PCR also served for identification of the genus Cryptosporidium for targeting a fragment of $145 \mathrm{bp} 18 \mathrm{~s} r \mathrm{RNA}$ gene, which is specific for three species (Cryptosporidium parvum, Cryptosporidium hominis, and Cryptosporidium meleagridis), according to the protocol of Fontaine et al. ${ }^{28,29}$ To make the PCR more specific and sensitive, two primers and one probe were used for each species.

\section{Cryptosporidium spp. by nested PCR and PCR-RFLP}

The nested PCR used two primer pairs amplifying a 179-271 bp 18s rRNA gene fragment. ${ }^{30}$ Restriction assays were performed in a $30 \mu \mathrm{L}$ volume with two units of restriction enzyme and $5 \mu \mathrm{L}$ of PCR product per reaction. Mixes were incubated in a heating block. Digestion products were visualized under ultraviolet light after $2 \%$ agarose gel electrophoresis and SYBR Green I staining. The enzymes used were Taq1 (Roche-Boehringer, Mannheim, Germany) and Ase1 (New England Biolabs, Beverly, MA). ${ }^{30}$

\section{PCR amplification of E. bieneusi}

The standard method for determining the genotype of E. bieneusi was based on the DNA sequence of the internal transcribed spacer (ITS) region of the rRNA gene. Genotypic analysis of E. bieneusi isolates was performed by sequencing the ITS portion of the rRNA gene. On the basis of these results, a phylogenetic interpretation regarding the sources and routes of transmission of the different groups of E. bieneusi genotypes was proposed. ${ }^{31}$

\section{Nucleotide sequencing of the ITS region of the $E$. bieneusi rRNA gene}

E. bieneusi genotypes were analyzed by nucleotide sequencing of the ITS region of the rRNA gene. A PCR product of $508 \mathrm{bp}$, containing $122 \mathrm{bp}$ of the small subunit rRNA, $243 \mathrm{bp}$ of the ITS region, and 143 bp of the large-subunit rRNA, was generated from 19 samples, using the primers MSP-3 [5'-GGA ATT CAC ACC GCC CGT C (A/G)(C/T)TAT-3] and MSP4B (5'-CCA AGC TTA TGC TTA AGT CCA GGG AG-3'), as described previously. ${ }^{32}$ PCR products were purified using a Concert Rapid PCR kit (Gibco-BRL, Gel Company Inc, San Francisco, CA) and sequenced in both directions using an ABI Big Dye Terminator kit (v 1.1) and an ABI 3100 automated sequencer (Applied Biosystems). The sequence accuracy was controlled by sequencing two PCR products from the same sample.

\section{Phylogenetic analysis}

The ITS sequences were obtained by comparing with those from previously published records in GenBank ${ }^{\circledR 33}$ using BLAST analysis (National Center for Biotechnology Information, Bethesda, MD). Multiple alignments of our new ITS nucleotide sequences and approximately 250 sequences were retrieved from GenBank (available by January 2012).

\section{Nucleotide sequence accession numbers}

Nucleotide sequences of the ITS region of the rRNA gene of one isolate for each genotype from DRC were deposited in the GenBank database. The accession numbers for the DRC isolates are JQ437573, JQ437574, and JQ437575 for the genotypes KIN1, KIN2, and KIN3, respectively.

\section{Statistical analysis}

Data were analyzed using the proportions (\%) for categorical variables and means with standard deviations for continuous variables. Differences were compared using the chi-square test for proportions and the Student's $t$-test for continuous variables. 
Analysis of variance was used to compare means across more than two groups. Odds ratios (OR) were calculated with $95 \%$ confidence intervals $(95 \% \mathrm{CI})$ using univariate analysis for potential risk factors (associated factors by contingency table) and logistic regression model (multivariate analysis) for independent determinants for opportunistic enteric parasites, after adjusting for confounding factors. A $P$ value $<0.05$ was considered statistically significant. All analyses were performed using Stata ${ }^{\circledR}$ software (v 11; StataCorp, College Station, TX) and SPSS software for Windows (v 19; IBM Corp, Armonk, NY).

\section{Results}

\section{Patient characteristics}

There were 242 participants in the study, 87 men (35.9\%) and 155 women $(64.1 \%)$, with a $2: 1$ women-to-men ratio. The mean age of the participants was $39.2 \pm 11.8$ years (range, 15-73 years).

\section{Prevalence of gastrointestinal parasites}

Table 1 summarizes the prevalence rates of pathogenic intestinal protozoa $(2 \%)$, nonpathogenic intestinal protozoa (10.6\%), and helminths $(2.8 \%)$.

\section{Prevalence of microsporidia and Cryptosporidium spp.}

The real-time PCR reported prevalence rates of $8.2 \%$ $(\mathrm{n}=20), 7.8 \%(\mathrm{n}=19), 0.4 \%(\mathrm{n}=1)$, and $5.4 \%(\mathrm{n}=13)$ for all microsporidia, E. bieneusi, E. intestinalis, and Cryptosporidium spp. among 242 stool specimens, respectively.

\section{Analysis of E. bieneusi and Cryptosporidium spp. genotypes}

Figure 1 shows isolates of five E. bieneusi strains yielded from the PCR product that were considered sufficient for the

Table I Prevalence of other intestinal nonopportunistic parasites in human immunodeficiency virus/acquired immunodeficiency syndrome patients

\begin{tabular}{lcc}
\hline Parasites & Total & $\%$ \\
\hline Pathogenic intestinal protozoa & & \\
Entamoeba histolytica & 3 & 1.2 \\
Giardia lamblia & 2 & 0.8 \\
Nonpathogenic intestinal protozoa & & \\
Entamoeba coli & 20 & 8.2 \\
Endolimax nana & 4 & 1.6 \\
lodamoeba butschlii & $\mathrm{I}$ & 0.8 \\
Intestinal helminths & & \\
Ascaris lumbricoides & 5 & 2 \\
Trichuris trichiura & $\mathrm{I}$ & 0.8 \\
\hline
\end{tabular}

nucleotide sequencing of the ITS region of the rRNA gene. We reported the five different genotypes for E. bieneusi (two previously called NIA1 and D and three new ones) in Table 2.

PCR-RFLP products had $0.4 \%(\mathrm{n}=1) C$. parvum and $1.6 \%(\mathrm{n}=4)$ had $C$. hominis among all 242 stool samples.

\section{Clinical and immune profiles}

Of the 242 participants, 88 (36.4\%) had asthenia, $83(34.3 \%)$ had diarrhea, and 75 (31\%) had CD4 counts $<100 \mathrm{cell} / \mathrm{mm}^{3}$.

There was a significant association between asthenia (53.6\%, $\mathrm{n}=15 ; P=0.04)$, chronic diarrhea $(57.1 \%, \mathrm{n}=16$; $P=0.007)$, Kaposi sarcoma $(75 \%, \mathrm{n}=21 ; P<0.0001)$, herpes zoster $(64.3 \% \mathrm{n}=18 ; P<0.001), \mathrm{CD} 4$ count $<100$ cells $/ \mathrm{mm}^{3}$ $(53.6 \%, \mathrm{n}=15 ; P=0.006)$, and the presence of opportunistic intestinal parasites (microsporidia + Cryptosporidium) in 28 patients. In addition, there was a significant relationship between digestive candidiasis, World Health Organization HIV stages, and the presence of microsporidia, E. bieneusi, and Cryptosporidium (results not shown).

Twelve (63.2\%) of the 19 E. bieneusi cases had diarrhea; seven of the 13 Cryptosporidium spp. cases had chronic diarrhea; three of the $C$. hominis cases had chronic diarrhea, one $C$. parvum case had diarrhea, and one $C$. hominis case did not have chronic diarrhea among the five different species identified by PCR-RFLP. The patients with the three new genotypes designated by GenBank as KIN1, KIN2, and KIN3 suffered from chronic diarrhea. The patients with these new genotypes had CD4 levels of $<200$ cells $/ \mathrm{mm}^{3}$.

\section{Epidemiological data}

Homosexual activity was not reported by the study population. There was a significant and negative association between the presence of opportunistic intestinal parasites $(n=28)$ and urbanization in the Kinshasa region (Figure 2).

The burden of opportunistic intestinal parasites decreased ( $P$ for trend $=0.023$ ) with the highest, the intermediate, and the lowest rates in the rural, semiurban, and urban areas, respectively, in Kinshasa residences.

The other univariate risk factors for the presence of opportunistic intestinal parasites were a CD4 count $<100$ cells $/ \mathrm{mm}^{3}$, no ART, exposure to farm pigs, drinking and recreational surface water, and public toilets (Table 3). The decreasing but significant power of the association (OR) was for exposure to pigs, ART, public toilets, surface water, and a CD4 count $<100$ cells $/ \mathrm{mm}^{3}$. Three new genotypes KIN1, $\mathrm{KIN} 2$, and KIN3 were found from 5 species of E. bieneusi. From the four Cryptosporidium species, one was identified as $C$. parvum and three as C. hominis. The sociodemographic 


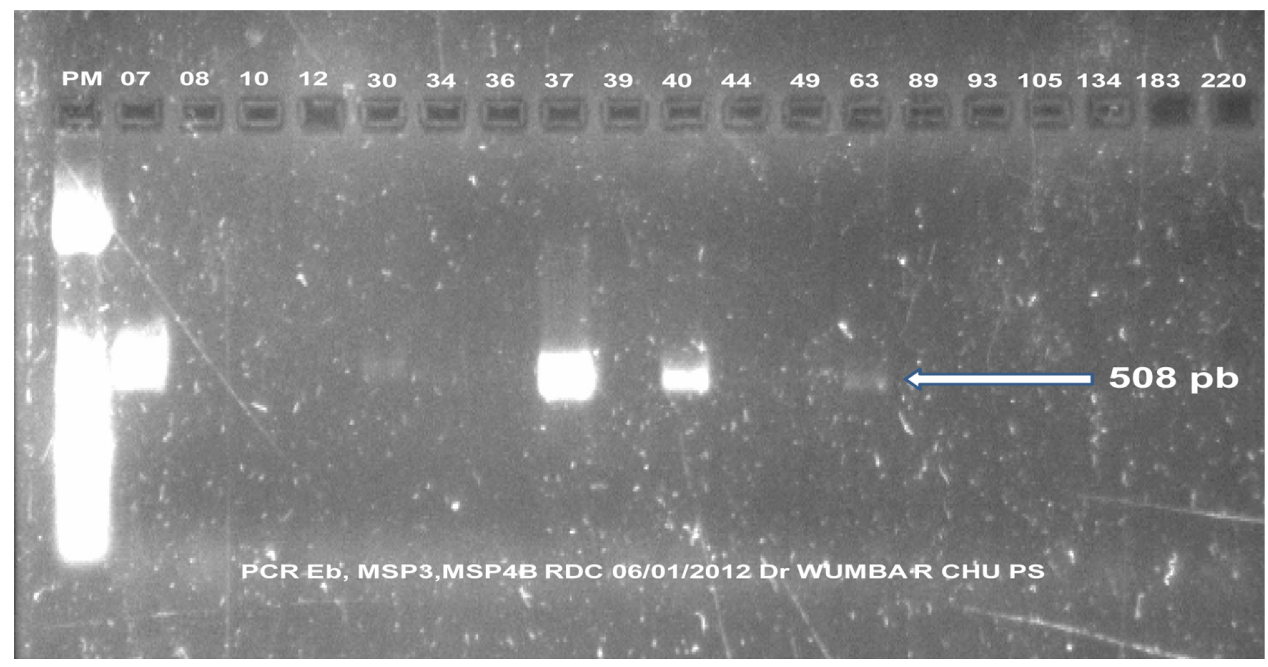

Figure I Positive results from polymerase chain reaction (PCR)-nucleotide sequencing of the internal transcribed spacer region of the Enterocytozoon bieneusi (Eb) rRNA gene, samples 7, 30, 37, 40, and 63.

data and food exposure were not associated with the presence of opportunistic intestinal parasites (results not shown).

After adjusting for Kinshasa residence, public toilets, and exposure to farm pigs in the multivariate analysis, only a CD4 count $<100$ cells $/ \mathrm{mm}^{3}$, no ART, and exposure to surface water were identified as significant and independent determinants for the presence of opportunistic intestinal parasites (Table 4).

\section{Discussion}

The present study reports the epidemiological, clinical, immune, and molecular profiles of opportunistic and nonopportunistic intestinal parasites in HIV-infected individuals in the DRC, Central Africa. Microsporidia and Cryptosporidium spp. were the important etiologic agents identified using both older and new laboratory methods for the diagnosis of parasitic diseases. ${ }^{34}$

In our African setting, the methods for the diagnosis of intestinal parasites in HIV/AIDS patients with chronic diarrhea have stagnated since 1981 until publication of our studies. ${ }^{21,22}$

Table 2 Different genotypes for Enterocytozoon bieneusi $(E b)$ identified by sequencing

\begin{tabular}{llll}
\hline Number 5 & PCR RT & $\begin{array}{l}\text { PCR MSP3/ } \\
\text { MSP4B }\end{array}$ & Genotypes \\
\hline 07 & $E b$ & Positive & KINI JQ437573 (new) \\
30 & $E b$ & Positive & KIN2 JQ437574 (new) \\
37 & $E b$ & Positive & KIN3 JQ437575 (new) \\
40 & $E b$ & Positive & NIAI (Espern et al ${ }^{43} ;$ \\
63 & $E b$ & & Wumba et al ${ }^{22}$ ) \\
\hline
\end{tabular}

Abbreviation: $\mathrm{PCR}$, polymerase chain reaction.
For many years, microscopy was the only method available for feces analysis. Further, indirect immunofluorescence with monoclonal antibodies was the only tool in the diagnosis of microsporidia before PCR began to be used in the DRC. Molecular-based approaches used in this study comprised extraction of DNA products: real-time PCR and nested PCR-RFLP. They were developed and applied for detecting microsporidia (E. bieneusi and E. intestinalis) and Cryptosporidium spp. in stool specimens from HIV-infected patients.

The burden of pathogenic intestinal protozoa (Entamoeba histolytica/dispar and Giardia lamblia), nonpathogenic intestinal protozoa (Entamoeba coli, Endolimax nana, and Iodamoeba butschlli), intestinal helminths (Ascaris lumbricoides and Trichuris trichiura), and opportunistic intestinal parasites (microsporidia, Cryptosporidium spp., and Isospora belli) in this study was lower than the prevalence of enteric parasites among HIV-individuals worldwide. ${ }^{1-22}$ The low prevalence of HIV/AIDS in the $\mathrm{DRC}^{35}$ may explain the

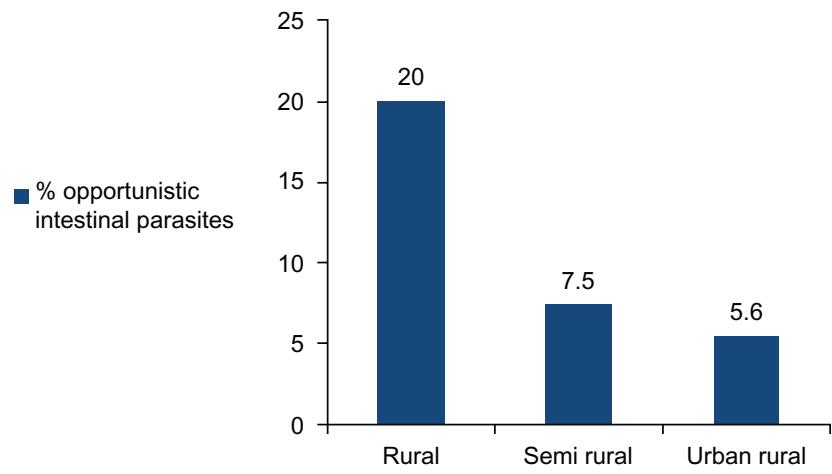

Figure 2 Relationship between the presence of opportunistic intestinal parasites and residence in the Kinshasa region. 
Table 3 Risk factors for Enterocytozoon bieneusi (Eb)/Cryptosporidium spp. (Csp) infections among human immunodeficiency virus/ acquired immunodeficiency syndrome patients (univariate analysis)

\begin{tabular}{|c|c|c|c|c|c|}
\hline Variables & Number tested & Number with Eb-Csp & OR & $95 \% \mathrm{Cl}$ & $\mathbf{P}$ \\
\hline CD4 count (cells $\left./ \mathrm{mm}^{3}\right)<100$ & 75 & $15(53.6)$ & 2.49 & $66.05-|66.8|$ & 0.006 \\
\hline No ART & 95 & $20(21.1)$ & 4.70 & $1.90-11.40$ & 0.0002 \\
\hline \multicolumn{6}{|l|}{ Domestic animals } \\
\hline Farm pigs & 8 & $5(10.7)$ & 4.99 & I. $10-22.6 \mathrm{I}$ & 0.02 \\
\hline \multicolumn{6}{|l|}{ Sanitary conditions } \\
\hline Surface water & 36 & $8(28.6)$ & 2.66 & $1.06-6.68$ & 0.03 \\
\hline Public toilets & 98 & $19(67.9)$ & 3.53 & $1.49-8.33$ & 0.002 \\
\hline
\end{tabular}

Note: Values in parenthesis indicate the percentage.

Abbreviations: ART, antiretroviral therapy; $\mathrm{Cl}$, confidence interval; OR, odds ratio.

present rates of microsporidia, E. bieneusi, E. intestinalis, and Cryptosporidium spp.

The very high prevalence of HIV/AIDS in countries of Southern Africa ${ }^{36,37}$ and homosexual activity in Western developed countries ${ }^{38-40}$ are reflected in the high prevalence (average 52\%) of Cryptosporidium and microsporidia among HIV patients from Zimbabwe, ${ }^{3}$ South Africa,,${ }^{15}$ and Italy. ${ }^{16}$

The expansion of the use of PCR techniques with HIV/AIDS patients in this study led to the identification of genotypes in microsporidia and Cryptosporidium spp. Microsporidia are single-celled, obligate intracellular parasites that are now reclassified from fungi ${ }^{41,42} E$. bieneusi was the most frequently used PCR-based method in this study. E. bieneusi is also the most common species reported to infect humans. ${ }^{42}$

In this study, the genotypes NIA1 and D of E. bieneusi were present in two patients. Espern et al in $2007^{43}$ and Wumba et al in $2010^{22}$ reported the NIA1 genotype and Breton et $\mathrm{al}^{31}$ reported the $\mathrm{D}$ genotype in 2007. Our study is the first to report three new genotypes of E. bieneusi, referred to as KIN1, KIN2, and KIN3. The tropical Kinshasa environment-based discoveries of the new genotypes were specific for chronic diarrhea, low CD4 levels, and no ART. The present positive association between opportunistic intestinal infection, including the highest proportion of E. bieneusi and diarrhea, may exhibit adaptation to individual cell types ${ }^{38,44}$ tropism of the epithelium of the small bowel and, the cryptic cells. ${ }^{44} 46$ The significant association between microsporidia and Cryptosporidium spp. and chronic diarrhea in HIV patients has now been reported in the literature. ${ }^{5,15}$

Further, the present study identified the potential (univariate) and independent risk factors of opportunistic intestinal parasites (microsporidia and Cryptosporidium spp.), confirming several studies in the literature. ${ }^{1-5,15-19,38}$ The environmental persistence for the distribution of microsporidia and the geographic distribution of opportunistic intestinal parasites ${ }^{42}$ are consistent with the present significant association between rural residences in the Kinshasa region of the DRC and the presence of opportunistic intestinal parasites. Exposure to surfaces (related to poverty in rural residences) was positively associated with opportunistic intestinal parasites.

This finding favors the detection of microsporidia spores in surface water. ${ }^{21,38,46-48}$ Consistent with the study by Likatavicius and Van de Laar in the literature, ${ }^{38}$ the present study found that exposure to farm pigs carries a potential risk of infection by opportunistic intestinal parasites. However, there is no formal proof of animal-human transmission of microsporidiosis, ${ }^{38}$ as exposure to pets and other animals was not identified in multivariate analysis.

This study cannot rule out exposure to public toilets as a potential risk factor for opportunistic intestinal parasites. ${ }^{38}$ There is an urgent need to eliminate microsporidia spores in the environment via fecal matter. ${ }^{21,38,46,49}$ Absence of ART and immune dysfunction in the present HIVinfected patients were a hallmark of microsporidia and Cryptosporidium spp infection. ${ }^{21,38,49}$ Conforming to

Table 4 Independent determinants of opportunistic enteric parasites (multivariate analysis)

\begin{tabular}{|c|c|c|c|c|c|}
\hline \multirow[t]{2}{*}{ Independent variables } & \multicolumn{2}{|c|}{ Nonstandardized } & \multirow[t]{2}{*}{ Wald chi-squares } & \multirow[t]{2}{*}{$\operatorname{Exp}(B)$ OR $(95 \% \mathrm{Cl})$} & \multirow[t]{2}{*}{$P$} \\
\hline & B SESE & & & & \\
\hline CD4, $<100$ vs $\geq 100$ cells $/ \mathrm{mm}^{3}$ & 1.519 & 0.500 & 9.211 & $4.60(1.70-12.20)$ & 0.002 \\
\hline ART, no vs yes & 1.613 & 0.490 & $|0.83|$ & $5.00(1.90-13.20)$ & $<0.001$ \\
\hline Surface water, yes vs no & 1.075 & 0.543 & 3.918 & $2.90(1.01-8.40)$ & 0.048 \\
\hline Constant & -1.979 & 0.491 & $16.25 \mid$ & & $<0.000$ I \\
\hline
\end{tabular}

Abbreviations: ART, antiretroviral therapy; $\mathrm{Cl}$, confidence interval; OR, odds ratio. 
results of different studies, ${ }^{21,50-55}$ an advanced stage of immunodepression for a CD4 count of $<100$ cells $/ \mathrm{mm}^{3}$ in the present study increased fivefold the risk of opportunistic intestinal parasites.

These findings will have implications for prevention, diagnosis methods, clinical spectra, and treatment among individuals with HIV. ${ }^{20,38,42,56,57}$ The prevention of microsporidia and Cryptosporidium spp. infection via individual and population-based prophylaxis should be established in terms of hygiene. Strict rules should be respected to avoid oro-fecal transmission, including hand washing, washing fresh vegetables, drinking boiled water, and limiting contact with animals susceptible to transmission of microsporidia and Cryptosporidium. ${ }^{38,47}$ The Government of the DRC is encouraged to treat drinking water sources with chloride or ozone. ${ }^{47}$ The diagnosis performance of opportunistic intestinal parasites might be established on the basis of the parasitological studies of feces.

The genus, genotypes, subgenotypes, and species could be identified by molecular methods in the DRC.

In the treatment of opportunistic intestinal parasites, the following medications are efficient: albendazole, benzimidazole derivatives, fumagillin, nitazoxanide, TNP-470, ovalicin, fluoroquinolones, antimitotics, polyamine analogs, and interferon gamma. ${ }^{38}$

ART should be available for all Congolese HIV patients, as it reduces the viral load and improves CD4 counts, as well as reducing prevalence, morbidity, and mortality related to HIV infection. ${ }^{25,38,56}$

This cross-sectional study may be limited to some degree, as the progression of immune status is not precise and, despite the use of PCR methods only for single stool specimens, the prevalence rates of $E$. bieneusi may be underestimated.

\section{Conclusion}

The prevalence of E. bieneusi and Cryptosporidium spp. is increasing in Kinshasa, DRC, and the findings of this study recommend epidemiological surveillance and prevention by hygiene. It is necessary to emphasize sensitive PCR methods and to treat microsporidia and Cryptosporidium spp.

\section{Acknowledgments}

We thank Professor Francis Derouin of the Hospital Saint Louis, Paris, France, and the students of Protestant University of Congo (UPC), Kinshasa, DRC, for sample collection, as well as Mrs Annie Claude Guillo-Olczyk, Isabelle Jolly, Isabelle Meyer, and Liliane Ciceron for excellent technical assistance. We also thank Mr Alain Gaulier and
Mrs Mireille Gaulier, Garenne Colombes, France, for social accommodation. We also acknowledge, with thanks, the physician directors and physicians of the four hospitals surveyed for their permission to carry out this study.

\section{Disclosure}

The authors have not received any funding or benefits from any industry, financing agency, or elsewhere, to conduct this study and report no conflicts of interest in this work.

\section{References}

1. Dwivedi KK, Prasad G, Saini S, Mahajan S, Lal S, Baveja UK. Enteric opportunistic parasites among HIV infected individuals: associated risk factors and immune status. Jpn J Infect Dis. 2007;60(2-3):76-81.

2. Bern C, Kawai V, Vargas D, et al. The epidemiology of intestinal microsporidiosis in patients with HIV/AIDS in Lima, Peru. $J$ Infect Dis. 2005;191(10):1658-1664.

3. Gumbo T, Sarbah S, Gangaidzo IT, et al. Intestinal parasites in patients with diarrhea and human immunodeficiency virus infection in Zimbabwe. AIDS. 1999;13(7):819-821.

4. Akinbo FO, Okaka CE, Omoregie R. Prevalence of intestinal parasitic infections among HIV patients in Benin City, Nigeria. Libyan J Med. 2010;5:doi:10.3402/ljm.v5i0.5506.

5. Rabeneck L, Gyorkey F, Genta RM, Gyorkey P, Foote LW, Risser JM The role of microsporidia in the pathogenesis of HIV-related chronic diarrhea. Ann Intern Med. 1993;119(9):895-899.

6. Leelayoova S, Subrungruang I, Rangsin R, et al. Transmission of Enterocytozoon bieneusi genotype a in a Thai orphanage. Am J Trop Med Hyg. 2005;73(1):104-107.

7. Assefa S, Erko B, Medhin G, Assefa Z, Shimelis T. Intestinal parasitic infections in relation to HIV/AIDS status, diarrhea and CD4 T-cell count. BMC Infect Dis. 2009;9:155.

8. Anane S, Attouchi H. Microsporidiosis: epidemiology, clinical data and therapy. Gastroenterol Clin Biol. 2010;34(8-9):450-464.

9. Nel ED, Rabie H, Goodway J, Cotton MF. A retrospective study of cryptosporidial diarrhea in a region with high HIV prevalence. J Trop Pediatr. 2011;57(4):289-592.

10. Abarca VK, López Del PJ, Peña DA, López GJ. Pet ownership and health status of pets from immunocompromised children, with emphasis in zoonotic diseases. Rev Chilena Infectol. 2011;28(3):205-210. Spanish.

11. Erhabor O, Obunge O, Awah I. Cryptosporidiosis among HIVinfected persons in the Niger Delta of Nigeria. Niger J Med. 2011;20(3):372-375.

12. Barrett DM, Steel-Duncan J, Christie CD, Eldemire-Shearer D, Lindo JF. Absence of opportunistic parasitic infestations in children living with HIV/AIDS in children's homes in Jamaica: pilot investigations. West Indian Med J. 2008;57(3):253-256.

13. Asmuth DM, DeGirolami PC, Federman M, et al. Clinical features of microsporidiosis in patients with AIDS. Clin Infect Dis. 1994;18(5):819-825.

14. McOliver CC, Lemerman HB, Silbergeld EK, Moore RD, Graczyk TK. Risks of recreational exposure to waterborne pathogens among persons with HIV/AIDS in Baltimore, Maryland. Am J Public Health. 2009;99(6):1116-1122.

15. Omoruyi B, Matongo F, Nkwetshana NT, Green E, Clarke AM, Ndip RN. Environmental and demographic risk factors associated with the prevalence of cryptosporidium infection in the Alice rural settlements of the Eastern Cape Province of South Africa: a pilot study. Rev Environ Health. 2011;26(2):127-133.

16. Voglino MC, Donelli G, Rossi P, et al. Intestinal microsporidiosis in Italian individuals with AIDS. Ital J Gastroenterol. 1996;28(7): 381-386. 
17. Del Aguila C, Navajas R, Gurbindo D, et al. Microsporidiosis in HIV-positive children in Madrid (Spain). J Eukaryot Microbiol. 1997;44(6):84S-85S.

18. Chacín-Bornilla L. Microsporidiosis: an emerging and opportunistic infection. Invest Clin. 2006;47(2):105-107.

19. Lobo ML, Xiao L, Antunes F, Matos O. Microsporidia as emerging pathogens and the implication for public health: a 10-year study on HIVpositive and -negative patients. Int J Parasitol. 2012;42(2):197-205.

20. Fisseha B, Petros B, WoldeMichael T. Cryptosporidium and other parasites in Ethiopian AIDS patients with chronic diarrhea. East Afr Med J. 1998;75(2):100-101.

21. Wumba R, Enache-Angoulvant A, Develoux M, et al. Prevalence of opportunistic digestive parasitic infections in Kinshasa, Democratic Republic of Congo. Results of a preliminary study in 50 AIDS patients. Med Trop (Mars). 2007;67(2):145-148.

22. Wumba R, Longo-Mbenza B, Mandina M, et al. Intestinal parasites infections in hospitalized AIDS patients in Kinshasa, Democratic Republic of Congo. Parasite. 2010;17(4):321-328.

23. World Health Organization. WHO case definitions of HIV for surveillance and revised clinical staging and immunological classification of $H I V$-related disease in adults aged 15 years or older. New Delhi, India: WHO SEARO Publication on HIV/AIDS; 2006.

24. Ritchie LS. An ether sedimentation technique for routine stool examinations. Bull U S Army Med Dep. 1948;8(4):326.

25. Henriksen SA, Pohlenz JF. Staining of cryptosporidia by a modified Ziehl-Neelsen technique. Acta Vet Scand. 1981;22(3-4):594-596.

26. Accoceberry I, Thellier M, Desportes-Livage I, et al. Production of monoclonal antibodies directed against the microsporidium. Enterocytozoon bieneusi. J Clin Microbiol. 1999;37(12):4107-4112.

27. Menotti J, Cassinat B, Porcher R, Sarfati C, Derouin F, Molina JM. Development of a real-time polymerase-chain-reaction assay for quantitative detection of Enterocytozoon bieneusi DNA in stool specimens from immunocompromised patients with intestinal microsporidiosis. J Infect Dis. 2003;187(9):1469-1474.

28. Fontaine M, Guillot E. Study of $18 \mathrm{~S}$ rRNA and rDNA stability by realtime RT-PCR in heat-inactivated Cryptosporidium parvum oocysts. FEMS Microbiol Lett. 2003;226(2):237-243.

29. Guitard J, Menotti J, Desveaux A, et al. Experimental study of the effects of probiotics on Cryptosporidium parvum infection in neonatal rats. Parasitol Res. 2006;99(5):522-527.

30. Coupe S, Sarfati C, Hamane S, Derouin F. Detection of cryptosporidium and identification to the species level by nested PCR and restriction fragment length polymorphism. J Clin Microbiol. 2005;43(3): 1017-1023

31. Breton J, Bart-Delabesse E, Biligui S, et al. New highly divergent rRNA sequence among biodiverse genotypes of Enterocytozoon bieneusi strains isolated from humans in Gabon and Cameroon. J Clin Microbiol. 2007;45(8):2580-2589.

32. Katzwinkel-Wladarsch S, Lieb M, Helse W, Löscher T, Rinder H. Direct amplification and species determination of microsporidian DNA from stool specimens. Trop Med Int Health. 1996;1(3):373-378.

33. Genbank ${ }^{\circledR}$ [database on the Internet]. Bethesda, MD: National Center for Biotechnology Information, US Library of Medicine; nd [updated November 11, 2011]. Available from: http://www.ncbi.nlm.nih.gov/ genbank/. Accessed May 29, 2012.

34. Ndao M. Diagnosis of parasitic diseases: old and new approaches. Interdiscip Perspect Infect Dis. 2009;2009:278246.

35. Kawashi FN, Longo-Mbenza B, Matanda NR, Nge-Okwe A, Fuele SM. Sociodemographic and semiological characteristics of ENT the sphere in patients with HIV/AIDS in Kinshasa, DR Congo. Pan Afr Med J. 2010;7:15

36. Mash B, Fairall L, Adejayan O, et al. A morbidity survey of South African primary care. PLoS One. 2012;7(3):e32358.

37. Mucheto P, Chadambuka A, Shambira G, Tshimanga M, Gombe N, Nyamayaro W. Determinants of nondisclosure of HIV status among women attending the prevention of mother to child transmission programme, Makonde district, Zimbabwe, 2009. Pan Afr Med J. 2011;8:51.
38. Likatavicius G, Van de Laar MJ. HIV and AIDS in the European Union, 2009. Euro Surveill. 2010;15(48):19737.

39. Cotte L, Rabodonirina M, Chapuis F, et al. Waterborne outbreak of intestinal microsporidiosis in persons with and without human immunodeficiency virus infection. J Infect Dis. 1999;180(6): 2003-2008.

40. Bergquist R, Morfeldt-Månsson L, Pehrson PO, Petrini B, Wasserman J. Antibody against Encephalitozoon cuniculi in Swedish homosexual men. Scand J Infect Dis. 1984;16(4):389-391.

41. Wittner M. Historic perspective on the microsporidia: expanding horizons. In: Wittner M, Weiss L, editors. Microsporidia and Microsporidiosis. Washington DC: American Society of Microbiology; 1999:24-31.

42. Didier ES, Stovall ME, Green LC, Brindley PJ, Sestak K, Didier PJ. Epidemiology of microsporidiosis: sources and modes of transmission. Vet Parasitol. 2004;126(1-2):145-166.

43. Espern A, Morio F, Miegeville M, et al. Molecular study of microsporidiosis due to Enterocytozoon bieneusi and Encephalitozoon intestinalis among human immunodeficiency virus-infected patients from two geographical areas: Niamey, Niger, and Hanoi, Vietnam. J Clin Microbiol. 2007;45(9):2999-3002.

44. Conteas CN, Berlin OG, Ash LR, Pruthi JS. Therapy for human gastrointestinal microsporidiosis. Am J Trop Med Hyg. 2000;63(3-4): 121-127.

45. Weber R, Bryan RT, Schwartz DA, Owen RL. Human microsporidial infections. Clin Microbiol Rev. 1994;7(4):426-461.

46. Franzen C, Muller A. Molecular techniques for detection, species differentiation, and phylogenetic analysis of microsporidia. Clin Microbiol Rev. 1999;12(2):243-285

47. Cheng HW, Lucy FE, Graczyk TK, Broaders MA, Mastitsky SE. Municipal wastewater treatment plants as removal systems and environment sources of human-virulent microsporidian spores. Parasitol Res. 2011;109(3):595-603.

48. Slodkowicz-Kowalska A, Graczyk TK, Tamang L, et al. Microsporidian species known to infect humans are present in aquatic birds: implications for transmission via water? Appl Environ Microbiol. 2006;72(7):4540-4544.

49. Lucy FE, Graczyk TK, Tamang L, Miraflor A, Minchin D. Biomonitoring of surface and coastal water for Cryptosporidium, Giardia and human-virulent microsporidia using molluscan shellfish. Parasitol Res. 2008;103(6):1369-1375.

50. Endeshaw T, Kebede A, Verweij JJ, et al. Intestinal microsporidiosis in diarrheal patients infected with human immunodeficiency virus-1 in Addis Ababa, Ethiopia. Jpn J Infect Dis. 2006;59(5):306-310.

51. Lebbad M, Norrgren H, Nauclér A, Dias F, Andersson S, Linder E. Intestinal parasites in HIV-2 associated AIDS cases with chronic diarrhea in Guinea-Bissau. Acta Trop. 2001;80(1):45-49.

52. Konate A, Minta D, Diarra M, et al. Intestinal parasitosis during AIDS diarrhoea. Bull Soc Pathol Exot. 2005;98(1):33-35.

53. Dworkin MS, Buskin SE, Davidson AJ, et al. Prevalence of intestinal microsporidiosis in human immunodeficiency virus-infected patients with diarrhea in major United States cities. Rev Inst Med Trop Sao Paulo. 2007;49(6):339-342.

54. Sarfati C, Bourgeois A, Menotti J, et al. Prevalence of intestinal parasites including microsporidia in human immunodeficiency virus-infected adults in Cameroon: a cross-sectional study. Am J Trop Med Hyg. 2006;74(1):162-164.

55. Hennequin C, Pialoux G, Bourre P, Dupont B. Microsporidiosis and acquired immunodeficiency syndrome (AIDS). Med Mal Infect. 1992;22(5):487-492.

56. Brady MT, Oleske JM, Williams PL, et al. Declines in mortality rates and changes in causes of death in HIV-1-infected children during the HAART era. J Acquir Immune Defic Syndr. 2010;53(1):86-94.

57. An W, Zhang D, Xiao S, Yu J, Yang M. Quantitative health risk assessment of Cryptosporidium in rivers of southern China based on continuous monitoring. Environ Sci Technol. 2011;45(11): 4951-4958. 
International Journal of General Medicine

Dovepress

\section{Publish your work in this journal}

The International Journal of General Medicine is an international, peer-reviewed open-access journal that focuses on general and internal medicine, pathogenesis, epidemiology, diagnosis, monitoring and treatment protocols. The journal is characterized by the rapid reporting of reviews, original research and clinical studies across all disease areas.
A key focus is the elucidation of disease processes and management protocols resulting in improved outcomes for the patient. The manuscript management system is completely online and includes a very quick and fair peer-review system. Visit http://www.dovepress.com/ testimonials.php to read real quotes from published authors.

Submit your manuscript here: http://www.dovepress.com/international-journal-of-general-medicine-journal 